\title{
Developing And Validating A Tool To Assess Ethical Decision-Making Ability Of Nursing Students, Using Rubrics
}

Apinya Indhraratana, Chulalongkorn University, Thailand Wannee Kaemkate, Chulalongkorn University, Thailand

\begin{abstract}
The aim of this paper is to develop a reliable and valid tool to assess ethical decision-making ability of nursing students using rubrics. A proposed ethical decision making process, from reviewing related literature was used as a framework for developing the rubrics. Participants included purposive sample of 86 nursing students from the Royal Thai Army Nursing College, experts in measuring and evaluation, and experts in nursing ethics, in Thailand. The results from the study showed that the content validity of the rubrics was adequate, 47 out of 48 scoring rubrics criteria had satisfied IOC's indexes over 0.5. Internal consistency using Cronbach's alpha coefficients was .865. Inter-rater reliabilities were between .804 and .903 , intra-rater reliability was .948.
\end{abstract}

Keywords: Ethical Decision-Making Ability; Rubric Assessment; Nursing Students

\section{INTRODUCTION}

urses regularly encounter ethical problems arise from their daily involvement in patient care.
(Numminen and Leino-Kilpi, 2007; Gastmans, 2002; Goelthal, Gastmans, \& Castelé, 2010). Rapid
technological advances creating complex care situations in which nurses are expected to autonomously make decisions in delivering good care to patients within the confines of strictly deadlines. (Goelthal, Gastmans, \& Castelé, 2010). Therefore nursing students need to be well prepared to be responsible professionals who are able to provide high quality care and capable of making autonomous ethical decision-making. (Numminen and Leino-Kilpi , 2007)

There has been a clear consensus by many educators and researchers that ethical decision-making is an essential component in nursing ethics curriculum. The goal of nursing ethics education is to produce a morally accountable practitioner who is skilled in ethical decision-making ((Numminen and Leino-Kilpe, 2007; Fry, 2008) However, there is paucity of research explicitly concerned with ethical decision making in nursing education. Likewise, the appropriate instrument to measure the ethical decision making process of nursing students is scarce in nursing literature (Numminen and Leino-Kilpe, 2007), thus the development of a reliable and valid tool to assess ethical decision-making is needed.

An ethical problem is difficult to deal with, solve, or overcome (Park, 2012). Many studies have revealed the complexity of ethical decision-making, which refers to the entire decision process, composed of many components and cognitive steps, starting from recognition of the ethical issues, follow by observation, analysis and reasoning, to making actual decision. (Park, 2012; Tsai et al., 2009; Numminen and Leino-Kilpe, 2007; Goelthal, Gastmans, \& Castelé, 2010) In order to develop a valid and reliable tool to measure ethical decision making, all potential components and cognitive steps must be explored, ethical decision-making ability should be evaluated in terms of the decision process as the well as the quality of the conclusion. (Park, 2012; Tsai et al, 2009). However, there is no ethical decision-making assessment tool built from a comprehensive evaluation of the cognitive steps used in the process or its underlying components 
This study was undertaken to develop a valid and reliable assessment tool, the ethical decision making (EDM) assessment rubrics, to measure nursing students' ability in ethical decision-making. Scoring rubrics were used to measure ethical decision-making ability in terms of the steps in the decision process and its underlying components. Rubrics are descriptive scoring schemes that are developed as a guide for qualitative rating of students efforts, which are authentic or complex works (Jonsson \& Svingby, 2007; Moskal \& Leydens, 2000). Benefits of rubrics as stated in literature are for example, increased consistency of judgment when assessing performance or authentic works. It was stated that a positive effect of using rubrics is the possibility to provide more valid judgment of performance than those achieved by means of conventional tests. (Jonsson \& Svingby, 2007)

The two research questions in this study are:

- $\quad$ To what extent do the EDM assessment rubrics demonstrate content validity?

- $\quad$ To what extent do the EDM scoring rubrics demonstrate reliability?

\section{METHOD}

This study consisted of two phases; the first phase was the developing of the EDM assessment rubrics, and testing for content validity and reliability. The second phase is the using of the the EDM assessment rubrics as a tool to assess ethical decision-making ability of nursing students before and after taking an ethics course. In this phase, the EDM assessment rubrics were tested for the ability to detect change of ethical decision-making ability of subjects after the intervention.

\subsection{Sample}

The participants in this study had two groups. The first group was purposive sample of 30 baccalaureate students of a nursing college in Bangkok, Thailand; all of the subjects were third years nursing students. This group participated in the developing of the EDM assessment rubrics. The second group was 56 purposive samples of nursing students of a nursing college in Bangkok, Thailand; this group participated in the second phase of study.

\subsection{Phase 1: Developing EDM assessment rubrics}

This study use concepts of ethical decision-making process reviewed from the literature as the framework to guide the development of the EDM assessment rubrics. Systematic ethical decision making models have been proposed by many authors. Toren and Wagner's ( 2010) ethical decision-making model includes 6 steps: 1) define the ethical dilemma; 2) clarify the personal and professional values, ethical principles and laws involved; 3) identify the alternatives for action; 4) choose an action; 5) initiate discussion about unresolved issues; and 6) generalize the solution to other similar cases. In addition, Park (2012) introduced an integrated ethical decision making model which also includes six steps:

- $\quad$ the identification of an ethical problem;

- the collection of additional information to identify the problem and develop solutions;

- $\quad$ the development of alternatives for analysis and comparison

- $\quad$ the selection of the best alternatives and justification;

- $\quad$ the development of diverse practical ways to implement ethical decision and actions; and

- the evaluation of effects and development of strategies to prevent similar occurrences.

This study defined the ethical decision making ability of nursing students as the ability of analytical thinking, to choose the best alternative when facing ethical conflict situations. The process is systematic, continuing step by step, and based on ethical justification. The ethical decision making ability composed of five components: perception of ethical conflicts; collecting necessary information; develop alternatives for analysis; decision-makings by choosing the best alternatives; and evaluation of the decision. In addition, 12 sub-components of ethical decisionmaking ability were identified: 
- $\quad$ Identifying related facts

- Identifying ethical conflict

- Identifying stakeholders

- Identifying necessary information for making decision.

- $\quad$ Identifying alternatives

- $\quad$ Analyzing and comparing alternatives

- $\quad$ Application of relevant ethical theories and principles.

- A decision-making by choosing best alternatives,

- Justification of the decision,

- $\quad$ Planning to implement the decision

- Identifying ways to evaluate the decision

- Identifying possible consequences of the decision.

The operational definitions of each sub-component were identified, and then descriptions of the scoring criteria of each level were stated. The EDM assessment rubrics employ four-point scales, varying from zero to three, and the scores assigned to each sub-component equally weighted.

\subsubsection{Content validity}

To answer the question, to which extent do the EDM scoring rubrics demonstrate content validity, expert opinions were used as empirical evidence to ensure the content validity. Four experts in measuring and evaluation and three experts in nursing ethics participated in validating the EDM assessment rubrics. The experts were asked to consider whether the scoring criteria addressed all aspects of the ethical decision making ability intended to measure and whether the descriptions of scoring rubrics criteria were appropriate with respect to the stated operational definitions. The experts rated the appropriateness of the scoring criteria; $1=$ appropriate, $0=$ uncertain, $-1=$ inappropriate. The Item Objective Congruence (IOC) indexes were calculated from the experts opinion. The results from the study showed that the content validity of the rubrics was adequate, 47 out of 48 scoring rubrics criteria had satisfied IOC's indexes over 0.5. Two experts suggested that some scoring criteria of the EDM assessment rubrics were rather abstract and need to be improved for more objectivity.

Table 1. The EDM assessment rubrics (example)

\begin{tabular}{|c|c|}
\hline $\begin{array}{l}\text { Components/ } \\
\text { sub-components }\end{array}$ & scoring criteria \\
\hline \multicolumn{2}{|c|}{ 1. Perception of ethical conflicts } \\
\hline \multirow[t]{4}{*}{$\begin{array}{l}1.1 \text { Identifying related } \\
\text { facts in the situation }\end{array}$} & $\begin{array}{l}\text { SCORE }=3 \text { : Identify facts related to the conflict arising from the situation correctly and } \\
\text { completely, including } \\
\text { 1. What is the conflict, who were affected by the conflict } \\
\text { 2. Causes of the conflict } \\
\text { 3. Consequences of the conflict }\end{array}$ \\
\hline & $\begin{array}{l}\text { SCORE }=2: \text { Identify most facts related to the conflict arising from the situation correctly, or no less } \\
\text { than } 70 \text { percents/ } 2 \text { out of } 3\end{array}$ \\
\hline & $\begin{array}{l}\text { SCORE }=1: \text { Identify some facts related to the conflict arising from in the situation correctly, or less } \\
\text { than } 70 \text { percents/ } 1 \text { out of } 3\end{array}$ \\
\hline & $\underline{\text { SCORE }=0}$ Not identify facts related to the conflict in the situation, \\
\hline \multirow[t]{4}{*}{$\begin{array}{l}1.2 \text { identifying ethical } \\
\text { conflicts }\end{array}$} & $\begin{array}{l}\text { SCORE }=3 \text { : Identify ethical conflicts in the situation correctly and completely, including } \\
\text { 1) Identify all values/rights/rules/ethical principles which are in conflict } \\
\text { 2) Clearly state the conflicts }\end{array}$ \\
\hline & $\begin{array}{l}\text { SCORE }=2: \text { Identify ethical conflicts in the situation mostly correct } \\
\text { e.g. 1. Identify all values/rights/rules/ethical principles which are in conflict } \\
\text { 2. Not clearly state the conflict. }\end{array}$ \\
\hline & $\begin{array}{l}\text { SCORE }=1: \text { Identify ethical conflicts in the situation somewhat correctly } \\
\text { e.g. .Identify at least one value/right/rule/ethical principle which are in conflict/ not clearly state } \\
\text { the conflict./identify some facts related to the conflict }\end{array}$ \\
\hline & $\underline{\text { SCORE }=0}$ Not identify ethical conflicts in the situation \\
\hline
\end{tabular}




\subsubsection{Reliability}

To assess the reliability of the EDM assessment rubrics, the author developed three ethical conflicts scenarios. Each scenario contained 12 open ended questions which asking nursing students to resolve ethical conflicts in the situations by using ethical decision making process (e.g. Identify ethical conflicts, collect necessary information; identify alternatives, making decision, and evaluation of the decision. In addition, the author developed a scoring manual, containing answers for each scenario corresponding to the rubric scoring criteria.

The purposive sample was 40 nursing students from the Royal Thai Army Nursing College who participated in this study. The subjects were asked to complete the three ethical conflicts scenarios with 36 openended questions. Three raters using EDM assessment rubrics and the scoring manual rated the data collected from subjects independently. The results reveal that inter-rater reliability using Pearson's correlation coefficient were .between 804 and .903, the intra--rater reliability using Pearson's correlation coefficient was. .948. One rater commented that the scoring manual was useful and helped increase consistency of scoring.

\subsection{Phase 2: Using of the EDM assessment rubrics}

The second phase of the study used one-group pre-test post-test design. An ethics course implemented as an extra -curricular project. The ethics course used various approaches to enhance ethical decision ability of the subjects such as group discussion of ethical issues, using ethical decision-making model, role-play, value clarification, application of relevance ethical theories and principle to guide moral reasoning, and reflections. The subjects attended the ethics course twice a week, for 4 weeks. Fifty-nine subjects completed both pre-test and post test in the study. The instruments using in this phase were the three ethical conflicts scenarios with 36 open ended questions, the EDM assessment rubrics, and the scoring manual. The mean, standard deviation, and paired t-test were used as the quantitative analysis.

\section{RESULTS}

The result from Table 1 show that, There was significantly statistical difference in test score of ethical decision making ability between before and after the intervention at .01 level.

\begin{tabular}{lcccccrr}
\hline \hline \multirow{2}{*}{ Ethical decision making ability } & \multicolumn{2}{c}{ Pre-test } & \multicolumn{2}{c}{ Pos-test } & \multirow{2}{*}{$\mathbf{d}$} & \multirow{2}{*}{$\mathbf{t}$} & \multirow{2}{*}{$\mathbf{p}$} \\
\cline { 2 - 5 } & mean & S.D. & mean & S.D. & & & \\
\hline Total $=108$ scores & 48.482 & 10.557 & 72.803 & 12.445 & 24.321 & -20.376 & .000 \\
\hline \hline
\end{tabular}

The results from Table 2 show that, there were significantly statistical differences in test scores of the five components: 1) perception of ethical conflicts; 2) collecting necessary information; 3) develop alternatives for analysis; 4) decision makings by choosing the best alternatives; and 5) evaluation of the decision, between before and after the intervention at .01 level

Table 2: Comparing mean scores of 5 components of ethical decision making ability of the subjects between pre-test and post test $(n=56)$

\begin{tabular}{|c|c|c|c|c|c|c|c|}
\hline \multirow{2}{*}{$\begin{array}{l}\text { Components of } \\
\text { ethical decision making ability }\end{array}$} & \multicolumn{2}{|c|}{ Pre-test } & \multicolumn{2}{|c|}{ Post-test } & \multirow[t]{2}{*}{ d } & \multirow[t]{2}{*}{ 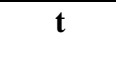 } & \multirow[t]{2}{*}{$\mathbf{p}$} \\
\hline & mean & S.D. & mean & S.D. & & & \\
\hline 1. perception of ethical conflicts (18) & 10.464 & 2.240 & 14.089 & 2.937 & 3.625 & -8.554 & .000 \\
\hline 2 collecting necessary information (18) & 8.268 & 2.666 & 12.179 & 2.961 & -3.911 & -11.244 & .000 \\
\hline 3. develop alternatives for analysis (27) & 9.607 & 2.721 & 17.786 & 3.793 & -8.178 & -16.797 & .000 \\
\hline 4. decision makings (27) & 11.857 & 3.900 & 17.179 & 4.148 & -5.321 & -9.843 & .000 \\
\hline 5. evaluation of the decision (18) & 8.286 & 2.730 & 11.571 & 2.230 & -1.321 & -10.33 & .000 \\
\hline
\end{tabular}




\section{CONCLUSION}

In conclusion, the EDM assessment rubrics can be a useful tool for evaluating ethical decision-making ability of nursing students. The research found that it could sensitively detect changes in ethical decision-making ability of nursing students after the intervention. However, developing reliable and valid rubrics to evaluate ability in ethical decision-making requires a significant investment of time and effort. The EDM assessment rubric developed in this study still need further improvement. Firstly, like other analytical scoring rubrics, the EDM assessment rubric, provides detailed scoring criteria and enable accounting for various aspects of ability in the ethical decision making process, but it also takes more time for raters to apply the criteria to each script to be marked. Secondly, the EDM assessment rubrics deal with the problem of objectivity, which need refinement and further research. Thirdly, although, the results showed satisfied inter-rater and intra--rater reliability, there is a question need to be answered; if the raters used the rubrics' scoring criteria alone, without the scoring manual, whether the rubrics would yield the same reliabilities?. In addition, the EDM assessment rubrics is in the initial stage of development, further researches can be conducted to examine other types of reliability and validity, whether the equally weighted scores assigned to each sub-component are appropriates, or should the cut-off score be identified for the EDM assessment rubrics.

\section{ACKNOWLEDGEMENTS}

With grateful acknowledgement for a grant received from The $90^{\text {th }}$ Anniversary of Chulalongkorn University Fund (Ratchadaphiseksomphot Endowment Fund).

\section{AUTHOR INFORMATION}

Apinya Indhraratana is a Ph.D. candidate in the department of educational research and psychology at Chulalongkorn University (Thailand). Her current research interests include research and development, and narrative research E-mail: apinyain@ hotmail.com

Wannee Kaemkate Ph.D., is associate professor of educational research and psychology at Chulalongkorn University. Her research interests include measurement and evaluation, and curriculum research and development. E-mail: wannee.k@gmail.com (Corresponding author)

\section{REFERENCES}

1. Boettger, R.K. (2010). Rubric use in technical communication: Exploring the process of creating valid and reliable assessment tools. IEEE Transactions of Professional communication 53 (1) March 2010: 4-17.

2. East, M. (2009). Evaluating the reliability of a detailed analytic scoring rubric for foreign language writing. Assessing Writing 14: 88-105.

3. Fry, S.T. (2008). Ethics in Nursing Practices: A guide to ethical decision making. Third edition. Singapore: Utopia.

4. Gallagher, A. (2006). The teaching of nursing ethics: content and method. Promoting ethical competence. In Davis, J.A., Tschudin, V., de Raeve, L. (eds) (223-239). Essential of Teaching and Learning in Nursing Ethics. Philadelphia: Churchill Livingstone-Elsevier.

5. Gastmans, C. (2002). A fundamental ethical approach to nursing: Some proposal for ethics education. Nursing Ethics 9 (5): 494-507.

6. Goelthal, S., Gastmans, C. Castelé, B.D. (2010). Nurses' ethical reasoning and behaviors: A literature review. International journal of Nursing Studies 47: 635-650.

7. Jonsson, A., Svingby, G. (2007). The use of scoring rubrics: Reliability, validity, and educational consequences. Educational Research Review 2: 130-144.

8. McAlpine, H., Krisjanson, L., and Poroch, D. (1997). Developing and testing of the ethical reasoning tool (ERT) an instrument to measure the ethical reasoning of nurses. Journal of advanced Nursing Research 25: 1151-1161. 
9. Moskal, B.M., and Leydens, J.A. (2000). Scoring Rubric Development: Validity and Reliability. Practical Assessment, Research \& Evaluation 7 (10). Retrieved March 8, 2012 from http://PAREonline.net/getvn.asp?v=7\&n=10

10. Numminen, O. H., Leino-kilpi, H. (2007). Nursing students' ethical decision-making: A review of the literature. Nurse Education Today 27: 796-807

11. Park, E. An integrated ethical decision-making models for nurses. Nursing Ethics. 19 (1): $139-159$.

12. Toran, O., and Wagner, N. (2010) Applying ethical decision - making tool to a nurse management dilemma. Nursing Ethics May 17 (3): 393-402

13. Tsai, T., Harasym, P.H., Coderre, S., Mclaughin, K. and Donnon, T. (2009). Assessing ethical problem solving be reasoning rather than decision making. Medical Education. 43: 1188-1197. 